Faculdade

de Ciências Econômicas UFRGS

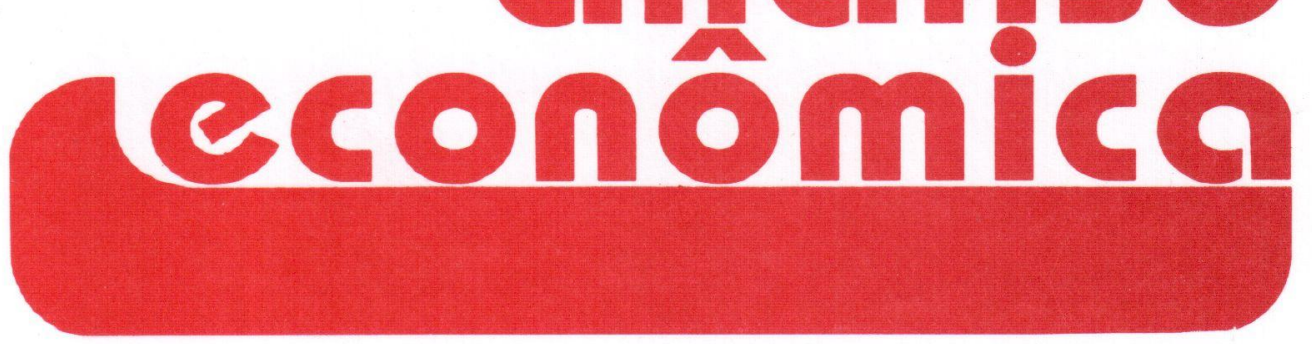

Balança Comercial e Capacidade

Produtiva da Indústria de Transformação

- Flávio Benevett Fligenspan

- Jeferson Luis Bittencourt

Breves Reflexões sobre a Relevância

da História da Teoria Econômica

- Gilberto Tadeu Lima

A Competitividade do Arroz Gaúcho

e seus Condicionantes

- Augusto M. Alvim

- Carlos G. A. Mielitz Netto

Uma Análise da Economia de Ricardo

- Liderau S. Marques Junior

A Estratégia de Substituição de

Importações Revisitada

- Alex Pereira Benício

- Joanílio Rodolpho Teixeira

The Refinements of the Orthodox Macroeconomic Theory and the Post Keynesian Theory

- Fernando Ferrari Filho

Instrumentos de Gestão Ambiental

- Jaildo Santos Pereira

- Vitor Emanuel Tavares

The Economic Implications for

Sustainable Mining

- Dina Franceschi

- James R. Kahn

Mudança Institucional e Estrutural na

Economia Brasileira do Início dos Anos Noventa

- Eduardo Simões de Almeida
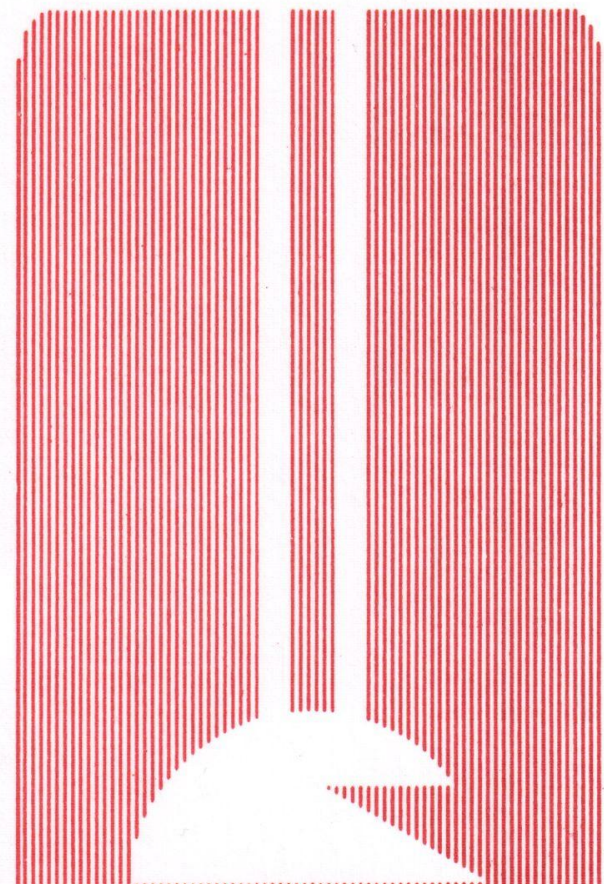

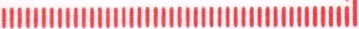
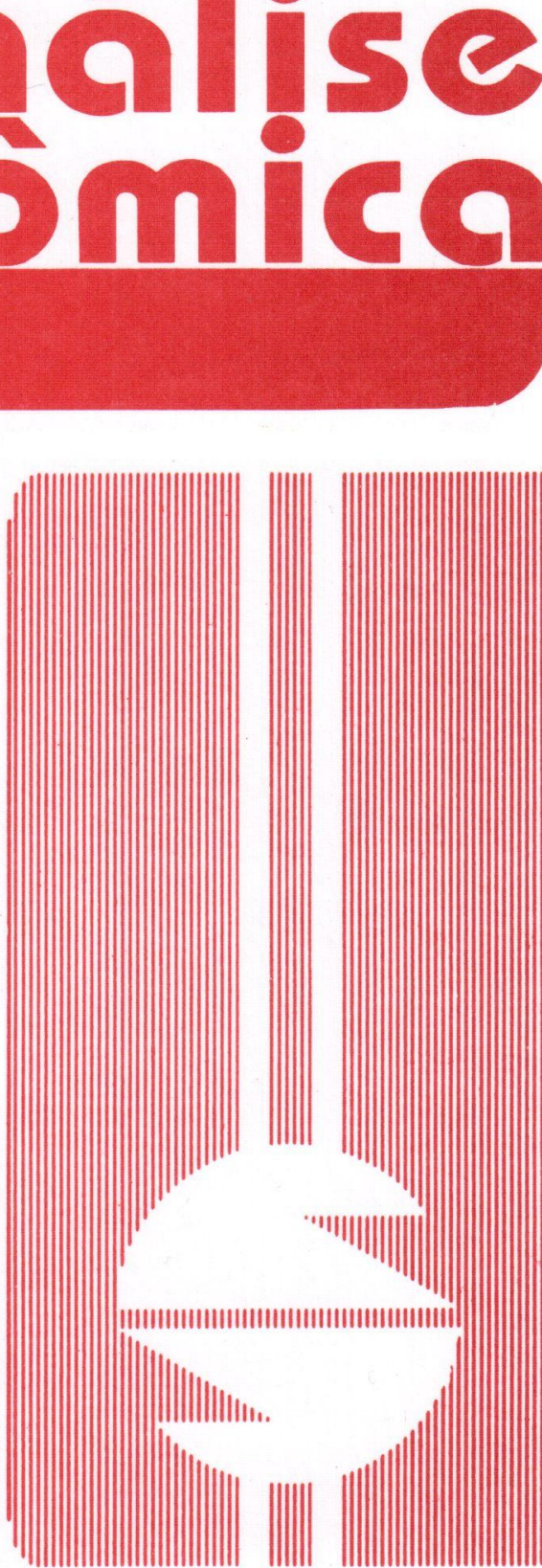
UNIVERSIDADE FEDERAL DO RIO GRANDE DO SUL

Reitora: Prof ${ }^{a}$. Wrana Maria Panizzi

FACULDADE DE CIÊNCIAS ECONÔMICAS

Diretora: Prof . Otilia Beatriz Kroeff Carrion

CENTRO DE ESTUDOS E PESQUISAS ECONÔMICAS

Diretor. Prof. Fernando Ferrari Filho

DEPARTAMENTO DE CIÊNCIAS ECONÔMICAS

Chefe: Prof. Luiz Alberto Oliveira Ribeiro de Miranda

CURSO DE PÓS-GRADUAÇÃO EM ECONOMIA

Coordenador. Prof. Marcelo Savino Portugal

CURSO DE PÓS-GRADUAÇÃO EM ECONOMIA RURAL

Coordenador. Prof. Carlos Guilherme A. Mielitz Netto

CONSELHO EDITORIAL: Achyles B. Costa, Aray M. Feldens, Carlos A. Crusius, Carlos G. A. Mielitz Netto, Eduardo A. Maldonado Filho, Eduardo P. Ribeiro, Eugênio Lagemann, Fernando Ferrari Filho, Gentil Corazza, Marcelo S. Portugal, Nali J. Souza, Otília B. K. Carrion, Paulo A. Spohr, Paulo D. Waquil, Pedro C. D. Fonseca, Roberto C. Moraes, Ronald Otto Hillbrecht, Stefano Florissi, Eleutério F. S. Prado (USP), Fernando H. Barbosa (FGV/RJ), Gustavo Franco (PUC/RJ), João R. Sanson (UFSC), Joaquim P. Andrade (UnB), Juan H. Moldau (USP), Paul Davidson (Univ. of Tennessee), Werner Baer (Univ. of lllinois).

COMISSÃO EDITORIAL: Eduardo Augusto Maldonado Filho, Fernando Ferrari Filho, Gentil Corazza, Marcelo Savino Portugal, Paulo Dabdab Waquil; Roberto Camps Moraes.

EDITOR: Gentil Corazza

EDITOR ADJUNTO: Pedro Silveira Bandeira

SECRETARIA: Fábio Sparremberger. Revisão de textos: Vanete Ricacheski.

FUNDADOR: Prof. Antônio Carlos Santos Rosa

Os materiais publicados na revista Análise Econômica são da exclusiva responsabilidade dos autores. É permitida a reprodução total ou parcial dos trabalhos, desde que seja citada a fonte. Aceita-se permuta com revistas congêneres. Aceitam-se, também, livros para divulgação, elaboração de resenhas e recensões. Toda correspondência, material para publicação (vide normas na terceira capa), assinaturas e permutas devem ser dirigidos ao seguinte destinatário:

PROF. GENTIL CORAZZA

Revista Análise Econômica - Av. João Pessoa, 52 CEP 90040-000 PORTO ALEGRE - RS, BRASIL 


\title{
A ESTRATÉGIA DE SUBSTITUIÇÃO DE IMPORTAÇÕES REVISITADA
}

\author{
Alex Pereira Benício ${ }^{1}$ \\ Joanilio Rodolpho Teixeira
}

\begin{abstract}
RESUMO
Neste trabalho são expostas resumidamente as principais noções econômicas embutidas na estratégia de desenvolvimento por substituição de importações. É mencionada uma nova metodologia de definição das estratégias comerciais - onde é considerada plausivel a combinação entre politicas de substituição de importações e de promoção às exportações - segundo a abordagem de Liang (1992. O trabalho é uma tentativa de incitar reflexões em torno do papel da politica comercial para a mudança no padrão das vantagens comparativas e, conseqüentemente, no estilo de desenvolvimento.
\end{abstract}

Cód. AEA: 430

Palavras-Chave: Substituição de Importações; Politica Comercial; Vantagens Comparativas Dinâmicas.

\section{ABSTRACT}

This paper surveys the basic ideas in the recent literature concerning the strategy of development which uses import substitution. We include in a new typology of trade strate gies the possibility of potential complementarily between export promotion and import substitution, as in Liang (1992). Our work is an attempt to stimulate a new look at trade policies. We question the static comparative advantaged assumption, in favour of a dynamic one and consequently, we provide a promising framework for formulating policy about development patterns.

AEA Code: 430

Key Words: Import substitution, trade policy, dynamic comparative advantages

\footnotetext{
${ }^{1}$ Os autores são do Departamento de Economia da Universidade de Brasilia e o apoio financeiro do CNPq para o desenvolvimento inicial desse trabalho é aqui reconhecido.
}

\begin{tabular}{|l|l|l|l|l|}
\hline Análise Econômica & ANO 17 & N. 31 & Março/99 & p. 77-99 \\
\hline
\end{tabular}




\section{1 - INTRODUÇÃO}

As políticas de industrialização por substituição de importações foram a coqueluche do Terceiro Mundo na década de 50 e meados dos 60, provocando profundas mudanças no quadro econômico e social. O protecionismo e a realocação induzida de fatores (via subsídios e outros mecanismos de intervenção estatal), associados à estratégia de substituição de importações, permitiram o surgimento de uma vasta gama de ramos industriais. Não obstante o impulso econômico nas fases iniciais, verificaram-se, posteriormente, crises no balanço de pagamentos e uma acentuada deterioração na qualidade dos bens consumidos internamente, levantando polêmicas sobre essa estratégia de desenvolvimento.

Na segunda metade da década de 60 , a políticas estruturalistas passaram a ser vistas com crescente descrédito, sendo substituídas gradativamente por medidas de promoção às exportações, ou de crescimento orientado "para fora". Ganharam destaque na aplicação deste receituário de crescimento econômico os paises do Sudeste Asiático, os Tigres Asiáticos. Entretanto diversos autores têm visto com reservas a classificação destes casos como de promoção às exportações "pura". Eles têm identificado nas estratégias de desenvolvimento dos países do Sudeste Asiático uma combinação de politicas substituidoras de importações e de promoção às exportações. Esta noção de politica comercial hibrida foi estudada mais aprofundadamente por Liang (1992). Neste trabalho sumarizamos as proposições dos primeiros estruturalistas e apresentamos a nova metodologia analítica de Liang, assim como as críticas a ela inerentes.

Nossa análise inicia-se com a apresentação das razões originais da defesa da estratégia de desenvolvimento por substituição de importações, em contraposição à ortodoxia das vantagens comparativas, na tradição ricardiana. Na seção 2 são apresentados os fundamentos do dinamismo atribuído ao crescimento por substituição de importações a partir da ótica da mudança no padrão de vantagens comparativas. Na seção 3 é feita uma análise das restrições à abordagem estruturalista. Na seção 4 é apresentado um esquema analítico de Liang. Finalmente, em seguida são apresentadas as conclusões, sumarizando as seções anteriores.

\section{2 - A ABORDAGEM ESTRUTURALISTA}

Para compreender melhor a orientação estruturalista de promover a industrialização por substituição de importações, é necessário ter em mente as razões que levaram à defesa da industrialização como o caminho para superar o subdesenvolvimento. Até meados deste século, prevalecia nos meios acadêmicos e na tecnocracia oficial a idéia clássica do comércio ex- 
terior, apoiado na teoria ricardiana das vantagens comparativas. Segundo essa abordagem, os países deveriam especializar-se ao máximo na produção daqueles bens cuja produtividade dos seus fatores de produção fosse maior (vantagens comparativas), e transacionar com o exterior o excedente produzido a fim de adquirir outros bens, em cuja produção não fossem tão eficientes. Eliminadas as barreiras ao livre comércio, essa especialização seria uma conseqüência natural e a população de cada país teria um inequívoco aumento no seu padrão consumo, decorrente do aumento generalizado na eficiência alocativa do livre comércio.

Isto é mostrado na Figura 2.1 a seguir, onde o eixo vertical representa quantidade de um bem industrializado $\mathrm{M}$, o qual pode ser produzido internamente, embora uma parte do montante consumido seja importada. No eixo horizontal está representada a quantidade do bem $X$ - digamos um bem primário - que é produzido internamente mas uma parte dessa produção é exportada. A curva $A_{1} B_{1}$ é a fronteira de possibilidades de produção, indicando as diversas combinações possíveis de produção, dadas as dotações dos fatores (terra, capital, mão-de-obra, etc.).

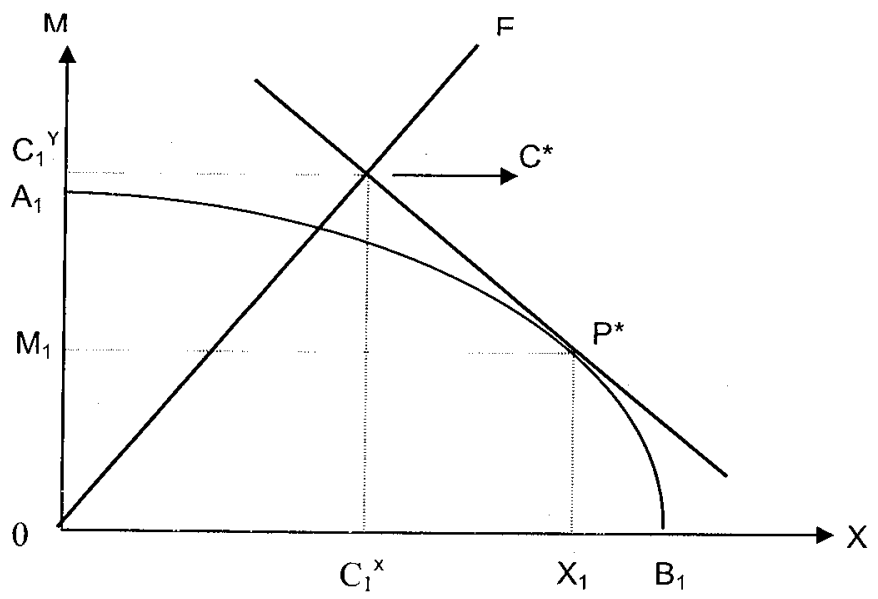

Figura 2.1 - Equilíbrio numa Economia Aberta

A reta negativamente inclinada que passa pelos pontos $P^{*} C^{*}$ indica a relação dos preços internacionais dos dois bens. No caso de pleno uso dos fatores produtivos (numa economia aberta de livre comércio) o ponto de tangência entre esta reta e a curva de possibilidades de produção mostra o ponto ótimo de produção, uma vez que estarão igualadas a taxa marginal 
de substituição entre os bens e a razão entre os seus respectivos preços. Nos termos da figura acima, a produção ótima da economia é aquela cuja combinação dos bens produzidos é $\left(M_{1}, X_{1}\right)$.

Já a reta positivamente inclinada OE é a "curva de renda-consumo", e indica os pontos de maximização da utilidade social (supondo curvas de indiferença social bem-comportadas) dadas as diferentes restrições orçamentárias decorrentes dos diversos niveis possiveis de utilização dos fatores para uma economia aberta. A fim de simplificar a exposição, estamos considerando a elasticidade-renda unitária (preferências homotéticas), daí ser uma reta a "curva" de renda-consumo; isto significa que, para um dado aumento na renda, a proporção do gasto com cada bem permanece constante. Uma vez que $\mathrm{P}^{*} \mathrm{C}^{*}$ é a "restrição orçamentária" da nossa economia, a interseção com a curva renda-consumo OE indicará o ponto ótimo de consumo de cada bem.

Podemos observar que o formato da curva $A_{i} B_{1}$ indica uma potencialidade maior do país na produção do bem primário, indicando que a vantagem comparativa desta economia está associada ao setor primárioexportador. No caso acima, a economia produzirá $X_{1}$ do bem primário e consumirá $C_{1}{ }^{x}$ do mesmo, sendo que a pródução adicional $\left(X_{1}-C_{1}{ }^{x}\right)$ será exportada. Com relação ao bem industrializado, será produzido $M_{1}$ e consumido $C_{1}{ }^{Y}$, sendo permitido este nível adicional de consumo $\left(C_{1}{ }^{y}-M_{1}\right)$ através das importações decorrentes das divisas obtidas pelas exportações do bem primário. Caso se tratasse de uma economia autárquica, a produção e o consumo de cada bem coincidiriam sobre a curva de possibilidades de produção, dependendo da relação de preços internos resultante. Entretanto o nivel de utilidade alcançado seria menor do que aquele obtido com algum nível de comércio.

Esta visão predominou na América Latina até meados deste século. Entretanto, segundo estudos de Raul Prebisch ${ }^{2}$ sobre a evolução dos termos de troca - para o período 1880/1945 - dos países subdesenvolvidos, constatou-se uma persistente deterioração do poder de compra destes países com relação aos países industrializados. A explicação para este fenômeno estaria na baixa elasticidade-renda da demanda dos países industrializados para os produtos primários; desta forma, um incremento na renda dos países industrializados decorrente - digamos - de uma melhoria tecnológica não traduzir-se-ia num aumento proporcional na procura por bens primários. Por outro lado, devido ao caráter monopolista/oligopolista de muitos países exportadores dos bens primários - associado à baixa elasticidade-preço da demanda por esses bens no mercado internacional, aumen-

2 Prebisch (1949). 
tos nas exportações desses produtos primários levariam a uma perda do poder de compra dos países subdesenvolvidos.

De acordo com Prebisch, a solução a longo prazo para o subdesenvol. vimento dos países "periféricos" seria a industrialização, pois a persistência no modelo agroexportador tenderia a distanciar cada vez mais o poder econômico entre os países "periféricos" e os países "centrais". Quanto à melhor estratégia para induzir a industrialização, prevaleceu na época o argumento da indústria nascente. De acordo com este argumento, a melhor estratégia para a implantação num país "periférico" de uma indústria seria através da garantia do mercado interno contra a concorrência estrangeira. A idéia era que - na ausência da proteção - os custos iniciais do estabelecimento da indústria não estimulariam os investidores privados a aventurar-se num ramo pioneiro. Tais custos estariam relacionados à presença de externalidades negativas como - por exemplo - o custo de treinamento de mão-deobra, sem a garantia para o capitalista privado de que esta mão-de-obra qualificada permaneceria na firma por um prazo suficientemente longo para garantir o retorno do investimento. Outro exemplo era o da inexistência de uma infra-estrutura (física e institucional) que permitisse condições de concorrência em igualdade com as indústrias tradicionais nos países industrializados.

Como mencionado em Fritsch \& Franco $^{3}$, o sucesso na promoção às indústrias nascentes dependerá da velocidade do aprendizado e da transferência de tecnologia ao país que substitui importações, pari passu o dinamismo da fronteira tecnológica. Estas condições podem ser expressas pelas seguintes funções:

$$
\begin{gathered}
C^{*}(t)=C_{0}{ }^{*}\left(w^{*}\right)-t \\
C(t)=C_{0}(w, V)-t=C_{0}(w, V)-\left({ }_{0}+{ }_{1}\right) t
\end{gathered}
$$

onde $C^{*}(t)$ e $C(t)$ são os custos totais de produção da indústria madura no exterior e da inclústria nascente no país em industrialização; $\mathrm{C}_{0}{ }^{*}$ e $\mathrm{C}_{0}$ são os custos iniciais de produção dessa indústria nos dois países; w e w são os respectivos salários pagos nesta indústria; os parâmetros e representam a velocidade do crescimento da produtividade; e $V$ representa o nível de integração vertical com outros setores domésticos relativamente ineficientes. A condição para o sucesso na implantação da indústria nascente - condição de Mill-Bastable - exigirá que o diferencial de custo entre $C(t)$ e $C^{*}(t)$ na forma da relação (3) - seja positivo no longo prazo:

\footnotetext{
${ }^{3}$ Fritsch \& Franco (1990: 82)
} 


$$
\int_{T_{0}}^{T_{0}^{*}} \exp (-Y t)\left[C(t)-C^{*}(t)\right] d t \geq 0
$$

Reproduzimos na Figura 2.2, a seguir, o gráfico apresentado por Fritsch \& Franco o qual ilustra a importância da velocidade do aprendizado na indústria nascente, frente à velocidade na redução nos custos internacionais, para a satisfação da expressão (3). Nos termos desta figura, a condição indicada pela equação (3) pode ser visualizada através da diferença entre as áreas B e A, situadas entre as curvas do custo de produção da indústria madura e da indústria nascente ao longo no tempo. A curva contjnua refere-se à indústria do país mais desenvolvido, precursora na produção deste bem. Ao longo do tempo, o seu custo de produção vai diminuindo, decorrente do aumento da produtividade. A indústria nascente no pais menos desenvolvido inicia suas atividades em $T_{0}$, apresentando custos de produção superiores ao da indústria madura no exterior, sobrevivendo graças à proteção contra a concorrência externa. À medida que esta indústria nascente for assimilando a tecnologia de produção e/ou ganhando economias de escala, seus produtos poderão concorrer com a indústria estrangeira em condições mais vantajosas. Assim, fica claro a importância da velocidade de aprendizado da indústria nascente e da sua geração de economias de escala - face à evolução dos preços internacionais - para a satisfação da condição indicada na expressão (3).

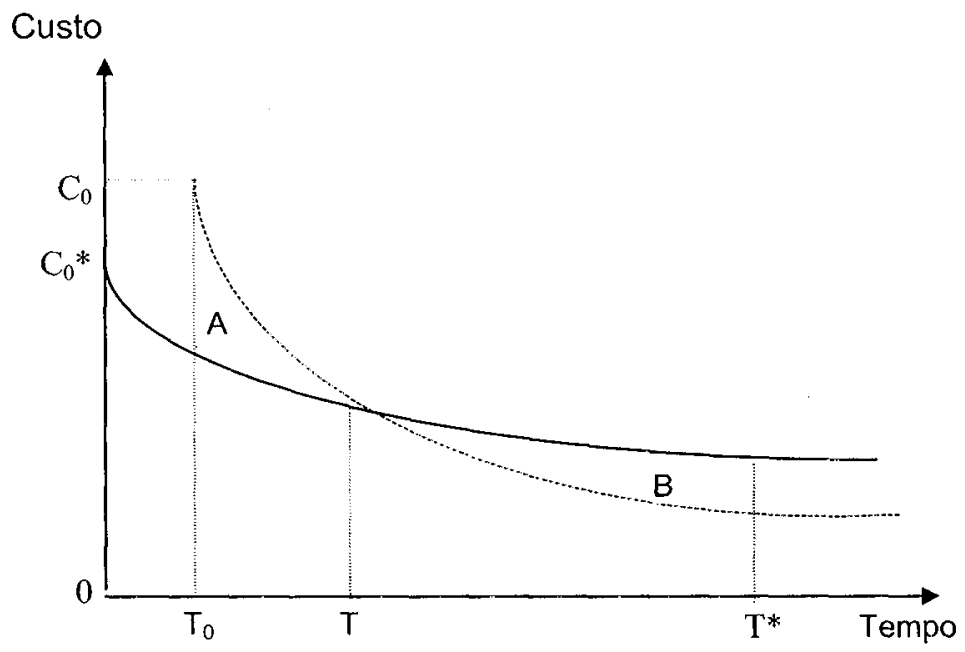


Figura 2.2 - Trajetória de uma Indústria Nascente

Entretanto o comércio de produtos industrializados mundial tem se caracterizado pelo progressivo incremento tecnológico e pela diversificação dos bens ofertados. As teorias do "ciclo do produto" argumentam que os novos produtos surgem nos países mais avançados, onde os padrões de consumo são mais sofisticados e estão mais capacitados tecnicamente para iniciar um novo ramo industrial ou introduzir inovações tecnológicas na produção de bens tradicionais. A aceleração no processo de diversificação dos produtos industriais implica choques de demanda para os setores tradicionais, alterando sensivelmente o quadro de inércia tecnológica considerada pela condição de Mill-Bastable -ver expressão (3) - para o sucesso na promoção da indústria nascente. Neste contexto, tal condição pode ser expressa como:

$$
\int_{N_{i}+L_{i}}^{N_{i+1}+L_{i+1}} \exp (-Y . t) \cdot\left[C(t)-C^{*}(t)\right] d t 0
$$

Como exposto por Fritsch \& Franco (1990), a Figura 2.3, a seguir, analisa a condição para o sucesso da promoção à indústria nascente de modo a incorporar as modificações introduzidas pela abordagem do ciclo do produto. A principal modificação em relação à Figura 2.2 refere-se ao surgimento de novos produtos concorrentes entre si, representados pelas curvas de custo $\mathrm{C}_{2}{ }^{*}(\mathrm{t})$ e $\mathrm{C}_{3}{ }^{*}(\mathrm{t})$ nos período $\mathrm{N}_{2}$ e $\mathrm{N}_{3}$. Tal como na figura anterior, existe uma defasagem temporal $\left(L_{2}\right.$ e $\left.L_{3}\right)$ entre o lançamento desse produto no país avançado e o início da sua produção no país retardatário, sendo possível apenas mediante a proteção contra as importações haja vista o atraso tecnológico refletido no diferencial de custos. Para efeitos de simplificação, consideramos que os dois países apresentam os mesmos custos iniciais de produção. Observamos que o lançamento de um novo produto não inviabiliza de imediato os produtos tradicionais, o que ocorre apenas quando o novo produto - decorrente das inovações tecnológicas - apresentar custos de produção inferiores ao do produto tradicional; na Figura 2.3

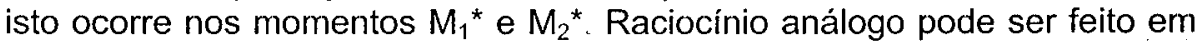
relação à indústria nascente - representada pelas curvas de custo $C_{1}(t)$, $\mathrm{C}_{2}(\mathrm{t})$ e $\mathrm{C}_{3}(\mathrm{t})$ - a qual somente terá sua produção inviabilizada pelo lançamento do novo produto, quando sua nova concorrente local apresentar custos de produção inferiores, o que ocorre nos momentos $M_{1}$ e $M_{2}$. 


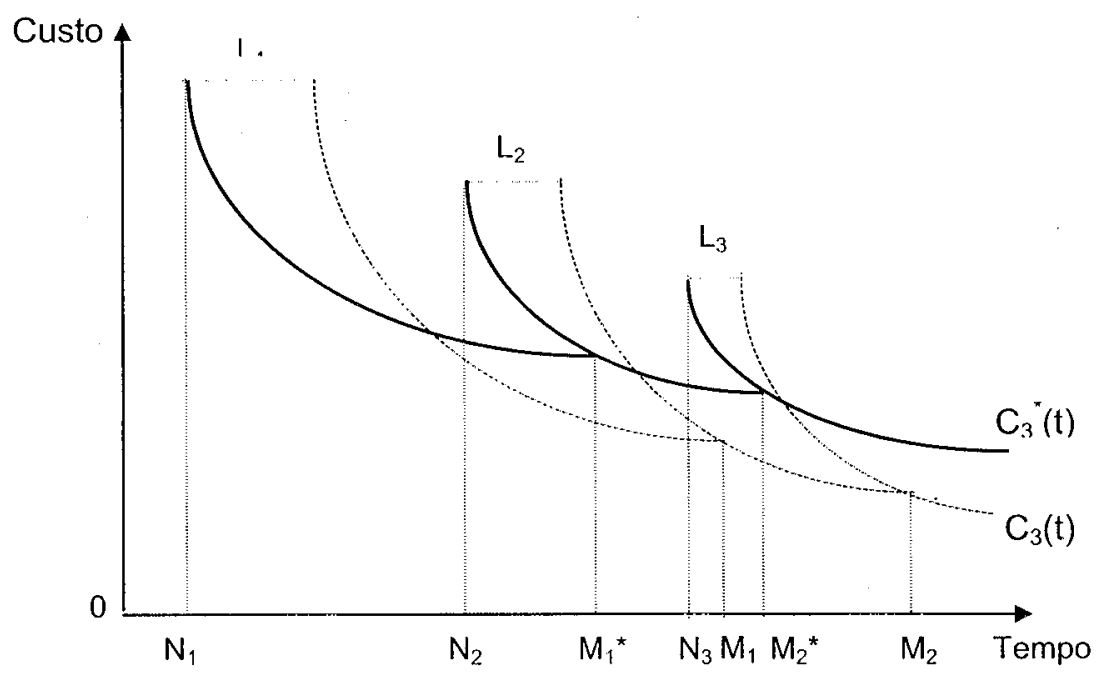

Figura 2.3 - A indústria nascente e o ciclo de produtos

Verificamos assim que, no âmbito do modelo do ciclo do produto, tornase mais rigorosa a condição para o sucesso da indústria nascente, embora a essência do argumento da defesa da sua proteção permaneça a mesma. Só que agora além da velocidade do aprendizado na indústria e da geração de economias de escala, a satisfação da condição de Mill-Bastable torna-se função também da velocidade do surgimento de novos produtos e da defasagem até o lançamento no país retardatário. Quanto mais rápida for a velocidade das inovações e menor for a defasagem para a instalação das novas indústrias nascentes, menores serão as chances para a satisfação da condição de Mill-Bastable.

$\mathrm{O}$ argumento da indústria nascente ensejou a industrialização por substituição de importações, a qual foi conceituada por Chenery (1960, p.640) como a redução do coeficiente de importações ${ }^{4}$. Este conceito é

${ }^{4}$ Existem muitas considerações que devem ser feitas a respeito deste conceito de substituição de importações, para uma análise mais detalhada ver Castelo Branco (1976: 8). Uma distinção mais formal entre politicas de substituição de importações e de promoção às exportações pode ser feita em termos da taxa de câmbio efetiva para importações 
móstrado graficamente na Figura 2.4, a seguir ${ }^{5}$. Partindo da situação inicial onde $o$ nivel de preços de livre comércio é $P_{1} C_{1}$, o ponto de equilíbrio da produção é $P_{1}$, onde são produzidos $X_{1}$ e $M_{1}$, respectivamente, dos bens primário e industrializado. Dada a curva de renda-consumo $0 \mathrm{E}$, o consumo de equilibrio se dá no ponto $C_{1}$, onde são consumidos $C_{1}{ }^{x}$ e $C_{1}{ }^{m}$, respectivamente, dos bens primário e industrializado.

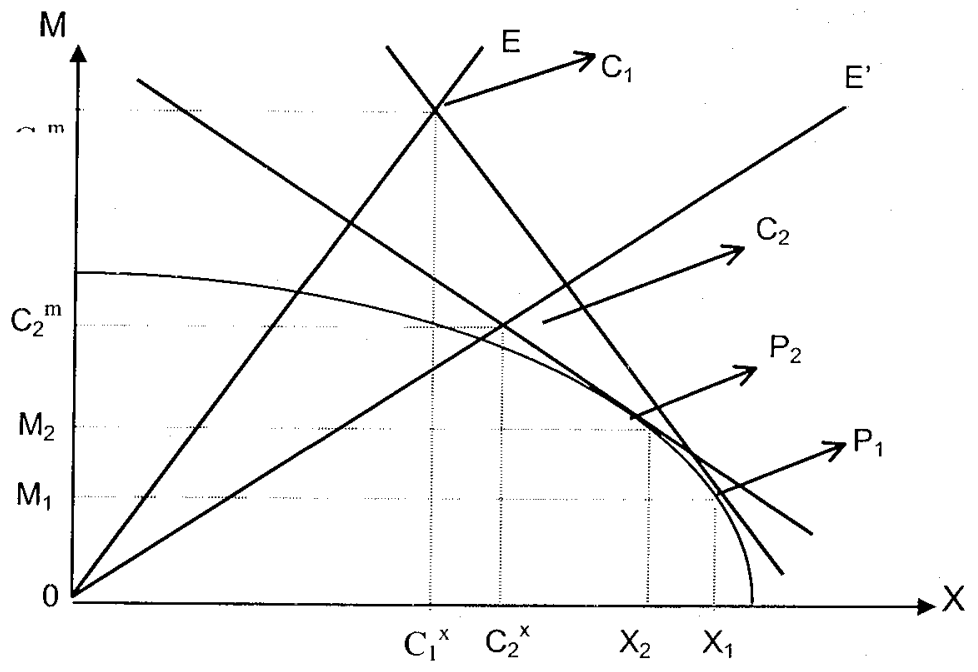

Figura 1.4 - O Efeito de uma tarifa

Agora consideremos a imposição de uma tarifa não-proibitiva sobre a importação dos bens industrializados, a fim de incentivar sua produção local. Automaticamente, a curva de preços internos relevante passa a ser aquela que liga o ponto $P_{2}$ (o qual indica a nova combinação ótima, do ponto de vista das empresas, da produção dos dois bens, no caso $X_{2}$ e $M_{2}$ ) ao ponto $\mathrm{C}_{2}$ (onde ocorre a interseção com a nova curva de renda-consumo

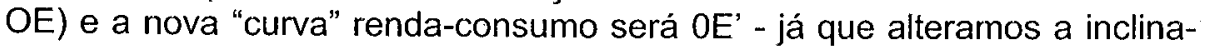
ção da restrição orçamentária. O resultado em termos da produção e do consumo é uma situação intermediária entre o equilíbrio no livre comércio cujos vetores de produção e consumo são $\left(X_{1}, M_{1}\right)$ e $\left(C_{1}{ }^{x}, C_{1}{ }^{m}\right)$ - numa situa-

$\left(E E R_{M}\right)$ e exportações $\left(E E R_{X}\right)$. Se $E E R_{M} / E E R_{X}>1$ considera-se que o pais segue uma política substitutiva de importações, caso contrário $\left(E E R_{M} / E E R_{X}<1\right)$ é uma política promotora das exportações. Södersten e Reed (1994). Mais adiante veremos uma alternativa a esta metodologia.

${ }^{5}$ Nossa análise grăfica foi inspirada em Desai (1969). 
ção de autarquia, onde a interseção da curva de renda-consumo com a reta de preços relativos fosse onde esta última tangenciasse com a curva de possibilidades de produção. $\mathrm{O}$ novo ponto de equilíbrio na produção é $\mathrm{P}_{2} \mathrm{e}$ o de consumo é $\mathrm{C}_{2}$.

Devido ao "empobrecimento" na economia, decorrente de uma realocação ineficiente dos fatores (por conta da imposição da tarifa de importação), o consumo do bem industrializado diminuiu de $\mathrm{C}_{1}{ }^{m}$ para $\mathrm{C}_{2}{ }^{\mathrm{m}}$, e o consumo do bem primário teve um pequeno acréscimo de $\mathrm{C}_{1}{ }^{x}$ para $\mathrm{C}_{2}{ }^{\mathrm{x}}$. Notemos que, com a proteção ao bem industrializado o seu preço interno subiu (relativamente ao bem primário) e sua produção interna também se elevou - já que tornou viável a produção destes bens por plantas industriais com um custo médio acima daquele produzido no exterior - de $M_{1}$ para $M_{2}$. Esta realocação dos fatores em direção ao bem industrializado fez diminuir a produção do bem primário de $X_{1}$ para $X_{2}$, já que estamos supondo pleno uso dos fatores. Definindo o coeficiente de importações como a razão entre as importações e a oferta interna (importação mais produção local), houve uma substancial redução no coeficiente de importação após a instituição da tarifa, o qual passou de $M_{1} C_{1}{ }^{m} / 0 C_{1}{ }^{m}$ para $M_{2} C_{2}{ }^{m} / 0 C_{2}{ }^{m}$.

Esta redução no coeficiente de importações não é considerada pelos estruturalistas como um verdadeiro processo de substituição de importações, já que o aumento na produção do bem industrializado foi decorrente de um deslocamento artificial das vantagens comparativas da economia em direção a este setor. Argumentam os estruturalistas que o verdadeiro processo de substituição de importações envolve uma modificação no padrão de vantagens comparativas, em que torna-se viável a produção de bens industrializados sem a necessidade de manutenção continuada da proteção. Esta modificação no padrão de vantagens comparativas seria resultado da ampliação e diversificação, com o passar do tempo, da capacidade produtiva no setor industrial, já que com a ampliação nos lucros deste setor os empresários teriam incentivos a investir no aumento da sua capacidade de produção, criando plantas industriais intensivas em capital, além do efeito do treinamento da mão-de-obra. Podemos representar graficamente este processo pelo deslocamento da curva de possibilidade produção "viesado" ao setor industrial, conforme é apresentado na Figura 2.5.

Podemos ver que com a nova curva de possibilidade de produção a relação de preços com livre comércio ainda resultará numa redução do coeficiente de importações; no caso acima, este coeficiente reduziu-se de $\mathrm{M}_{1} \mathrm{C}_{1}{ }^{\mathrm{m}} / 0 \mathrm{C}_{1}{ }^{\mathrm{m}}$ para $\mathrm{M}_{2} \mathrm{C}_{2}{ }^{\mathrm{m}} / 0 \mathrm{C}_{2}{ }^{\mathrm{m}}$. A proposição fundamental é que, após um periodo de transição, a nova estrutura produtiva industrial não necessitará dos incentivos protecionistas, já que o setor industrial estará dotado de uma disponibilidade de recursos que o tornarão mais competitivo (deslocamento no padrão de vantagens comparativas) e reduzirá a dependência do exteri- 
or, rompendo a tendência de contínua deterioração nos termos de troca. Quanto à questão da produtividade, argumenta-se que o treinamento contínuo da mão-de-obra, nas atividades incipientes, endogeinizaria o processo de inovação tecnológica. Este é um argumento das teorias do crescimento econômico da linha learning-by-doing.

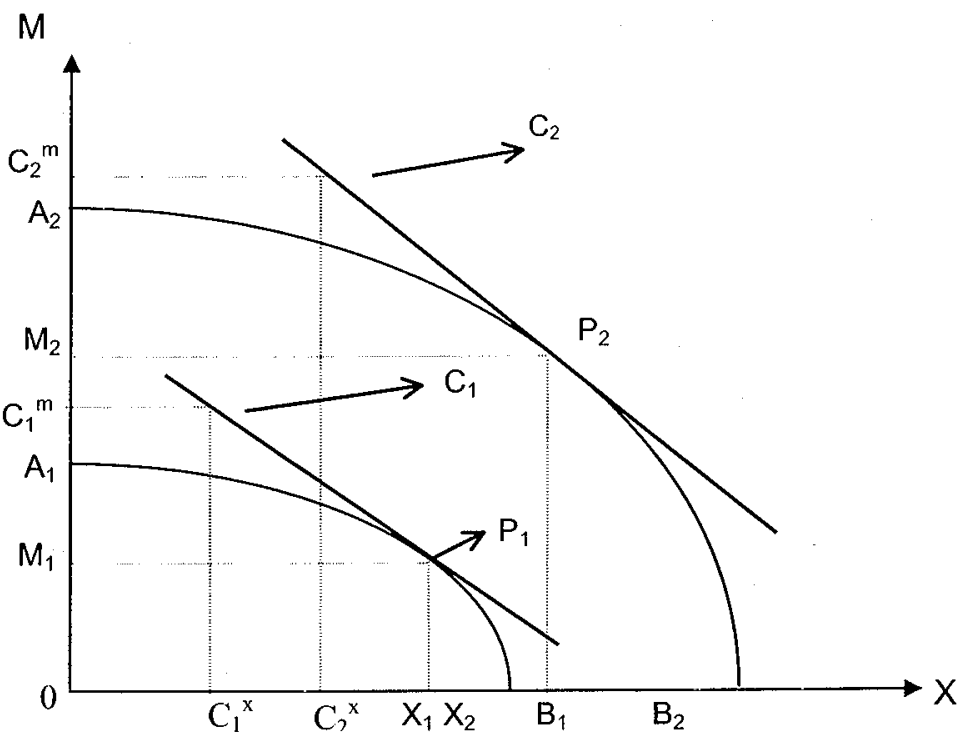

Figura 2.5 - Deslocamento na curva de transformação

\section{3 - CRÍTICAS À SUBSTITUIÇÃO DE IMPORTAÇÕES}

A análise estruturalista - ao considerar as vantagens comparativas em termos dinâmicos - racionalizou a aplicação de práticas protecionistas em diversas partes do mundo subdesenvolvido, indo muito além da América Latina. A diferença ficou por conta da coordenação das práticas intervencionistas e de estímulo à indústria local. No caso brasileiro, em especial a estratégia de crescimento por substituição de importações, ficou 
consagrada no Plano de Metas (1956-60), de Juscelino Kubitschek ${ }^{6}$. Este plano concentrou cerca $71,3 \%$ dos seus recursos orçamentários aos setores de infra-estrutura (energético e de transportes) e $22,3 \%{ }^{7}$ a setores da indústria básica. Priorizou-se o crescimento por substituição de importações, através da imposição de barreiras tarifárias e não-tarifárias, tendo a indústria automobilística como o setor dinâmico. A característica principal do plano era o inter-relacionamento entre as metas. Neste ponto, cabe destacar que teve importância fundamental a influência do Grupo Misto BNDECEPAL (1953-56) que formulou diversos estudos relativos à implantação da indústria básica e a realização de diversas projeções que nortearam as metas consubstanciadas no Plano, atentando enfaticamente para a importância da execução de um plano de investimentos global com alto grau de coordenação entre os projetos individuais.

Por caracterizar-se pelo alto grau de encadeamento, o apoio decidido à indústria automobilística foi peça fundamental no desenvolvimento industrial no período, que de uma taxa de crescimento de 5,5\% em 1956 chegou a $16,8 \%$ em 1958 e $10,6 \%^{8}$ em 1960 . No periodo $1957-61$, o PIB global cresceu a uma taxa anual de $8,2 \%$, bem acima da sua média histórica. Igualmente importante foi a modificação na estrutura produtiva, a qual permitiu reduzir o coeficiente de importações a $7 \%$ em $1960^{9}$, embora esta estatística esteja sujeita às medidas protecionistas vigentes neste período.

Entretanto, contraditoriamente, apesar desse aparente sucesso na redução da dependência externa, a balança comercial deteriorou-se: de um superávit de US\$ 437 milhões em 1956 chegou a um déficit de US\$23 miIhões em 1960. Aí entra em cena um dos argumentos dos críticos a esta estratégia de desenvolvimento. A primeira fase da produção substitutiva ligada aos bens de consumo não-duráveis - é relativamente fácil devido à intensidade em fatores abundantes nos países subidesenvolvidos (como mão-de-obra não-qualificada, baixo nível tecnológico e pequena escala produtiva). Entretanto a segunda fase - relacionada aos bens de consumo duráveis - requer unidades produtivas mais intensivas em capital e insumos básicos, os quais os países em desenvolvimento são reconhecidamente deficientes $^{10}$

\footnotetext{
${ }^{6}$ O Plano de Metas é considerado por muitos autores como um exemplo de estratégia de crescimento por substituição de importações bem-sucedida. Morley e Smith atribuem à substituição de importações cerca de $44,0 \%$ do aumento na demanda total da indústria manufatureira no periodo 1949-64. Morley-Smith (1970: 733).

${ }^{7}$ Orenstein e Sochaczewski (1992: 177).

${ }^{8}$ Dados extraidos de Abreu (1992:403).

${ }^{9}$ Orenstein e Sochaczewski (1992: 180).

${ }^{10}$ Williansom (1993: 249).
} 
Para melhor compreensão deste ponto, é útil a interpretação do conceito de Custo dos Recursos Domésticos (CRD) para a geração/economia de divisas. A taxa $\mathrm{CRD}_{i}$ de um determinado bem $i$ indica o custo em moeda nacional dos fatores internos requeridos na geração de uma unidade de divisa estrangeira liquida, caso o bem i seja exportado; ou, alternativamente, o custo em moeda local utilizado para produção interna deste bem caso ele seja importado ${ }^{11}$. Percebe-se que a viabilidade da produção local de um bem (em termos da maximização de divisas) requererá que a sua taxa CRD seja menor que a unidade, e que a escolha dos setores incentivados para maximização de divisas seja aquele com menor coeficiente CRD. Os opositores da estratégia substitutiva de importações acreditam que a taxa CRD para as exportações dos bens industriais produzidos após a primeira fase de substituição de importações é menor do que a taxa CRD dos bens da segunda fase de substituição de importações. Isto seria decorrente da maior capacidade de absorção do mercado externo (que é o mercado dinâmico da estratégia de crescimento voltada "para fora"), comparativamente à do mercado interno (no caso da estratégia substitutiva de importações) ${ }^{12}$.

As razões para este comportarnento da taxa CRD, na segunda fase do processo de substituição de importações, dizem respeito à perda de eficiência geral na economia ao permitir a sobrevivência de unidades produtivas com custos médios elevados, as quais não seriam viáveis numa situação de livre mercado. Uma outra fonte de ineficiência pode estar relacionada ao baixo uso das economias de escala; ou seja, como a segunda fase do processo substitutivo de importações se concentra em setores (como siderurgias, indústria petroquímica, etc.) que exigem elevada escala de produção, se o mercado interno for suficientemente pequeno poderão instalar-se unidades produtivas com uma escala de produção abaixo do tamanho mínimo ideal.

Alternativamente, se o mercado interno for grande o suficiente para obter ganhos de economia de escala, mas o mesmo caracterizar-se por setores monopolistas/oligopolitas, novamente surgem ineficiências decorrentes do poder de manipulação dos preços dos grupos estabelecidos. Nas palavras de Prebisch:

(...) the proliferation of industries of every kind in a closed market has deprived the Latin American countries of the advantages of specialization and economies of scale, and owing to the protection afforded by excessive tariff duties and restrictions, a healthy form of internal competition has failed to develop to the detriment of efficient production $^{13}$.

\footnotetext{
${ }_{11}$ Paula Pinto et. Alli (1994: 4).

${ }^{12}$ Williansom (1993: 250).

${ }^{13}$ Prebisch (1963:71) apud Mitra (1974: 527).
} 
Destacamos ainda que, se a proteção a estas indústrias perpetuar-se indefinidamente, o empresário poderá não ter incentivos a incrementar a produtividade da sua firma, e assim o protecionismo acabará não gerando o processo - segundo a literatura learning-by-doing - de inovação tecnológica, deixando inalteradas as vantagens comparativas. Este ponto é importante porque contraria as expectativas dos defensores do argumento das vantagens comparativas dinâmicas.

Argumenta-se também que, paradoxalmente, ao buscar a autosuficiência, a rigidez causada na pauta de importações de bens de capital e de insumos básicos resultará numa vulnerabilidade cada vez maior a choques externos. Isto se deve à rigidez na pauta de importações das economias voltadas "para dentro", constituída sobretudo por bens de capital e insumos básicos essenciais à manutenção da atividade econômica interna. Neste contexto, um choque externo resultará num abalo à atividade interna, já que não existe tanta margem para redução nas importações do que numa economia voltada "para fora", em que sua pauta de importações compõe-se de muitos bens de consumo facilmente suscetíveis de corte.

Também importante neste debate é a indicação de que o processo de substituição de importações é concentrador de renda. Pelo teorema de Stolper-Samuelson, pode-se mostrar que a imposição de uma tarifa sobre a importação de um determinado bem resultará no aumento da remuneração do fator no qual o bem é intensivo ${ }^{14}$. A explicação intuitiva é que com a proteção a este bem, sua produção local é incentivada, aumentando - por extensão - mais acentuadamente a demanda pelo fator no qual ele é intensivo. Com este aumento da demanda, a remuneração do fator tende a crescer comparativamente à do outro fator. Ocorre que os produtos industriais, especialmente aqueles característicos da segunda fase da substituição de importação, são mais intensivos em capital.

A abordagem estruturalista, apresentada na seção 3, partia de um modelo bissetorial, no qual todos os setores da economia seriam produtores de bens exportáveis ou importáveis, podendo ambos os bens serem consumidos internamente. $\mathrm{Na}$ seção 4 a seguir, apresentamos uma nova abordagem de política comercial desenvolvida por Liang (1992); esta abordagem é baseada num modelo trissetorial, em que haveria um setor produtor de bens non-tradeables e outros dois setores tradeables, produtores de exportáveis e de bens competidores com as importações, como na seção 3. Com base neste modelo, são identificadas cinco estratégias comerciais mutuamente exclusivas, abrindo a possibilidade teórica de estratégias comerciais híbridas.

${ }^{14}$ Williamson (1993: 45) 


\section{4 - A ABORDAGEM DE LIANG}

A análise baseada num modelo bissetorial como aquele apresentado até agora, sugere as estratégias comerciais baseadas na substituição de importações (SI) e na promoção às exportações (PE) como bipolares. Isto fica claro na Figura 4.1 seguinte, onde são relacionadas a curva de possibilidades de produção $A B$ e a linha representativa da razão de preços internacionais entre bens exportáveis e importáveis, $\mathrm{PF}^{15}$. $\mathrm{O}$ eixo vertical representa, como nas figuras anteriores, a produção dos bens importáveis; o eixo horizontal representa a produção de bens exportáveis. Em condições de livre mercado, o equilíbrio na produção ocorre em $\mathrm{P}^{*}$, onde os preços relativos internos entre bens exportáveis e importáveis igualam-se aos preços internacionais.

Representando $E R_{m}$ e $E R_{x}$ como a taxa de câmbio para os bens importáveis e exportáveis, nos pontos à esquerda de $P^{*}$ sobre a curva $A B$ a taxa de câmbio para os bens importáveis será maior que a taxa para os bens exportáveis. Isto significa que a "valorização" cambial dos bens importáveis torna mais atraente a produção interna comparativamente aos bens exportáveis sob a condição de livre comércio. Desta forma, recursos internos são deslocados das atividades exportadoras em direção às atividades que competem com as importações. $O$ inverso acontece para os pontos situados sobre a curva $A B$ à direita de $P^{*}$. Esta análise é semelhante àquela empreendida nas figuras anteriores, só que agora distinguimos os pontos onde a estratégia comercial é orientada "para dentro" (ou seja, SI, onde $\left.E R_{m}>E R_{x}\right)$, onde é livre comércio $\left(P^{*}\right)$ e onde a estratégia é orientada "para fora" (PE, onde $\left.E R_{x}>E R_{m}\right)$.

Uma análise nestes termos deixa claro a relação dual entre as duas estratégias comerciais. Entretanto, seguindo o raciocínio de Liang (1992:451), uma economia pode ser dividida em três setores: de bens exportáveis $(X)$, importáveis $(M)$ e de bens não-comercializáveis com o exterior $(H)$. Dado que a política econômica afeta não somente a relação de preços entre setores produtores de bens comercializáveis, mas também entre comercializáveis e não-comercializáveis, definiremos as estratégias comerciais num modelo trissetorial. Assim, a produção de cada bem comercializável é função dos preços relativos entre os bens comercializáveis e o bem doméstico:

$$
X=f\left(P_{m} / h, P_{x} / h\right), \quad M=g\left(P_{m} / h, P_{x} / h\right) .
$$

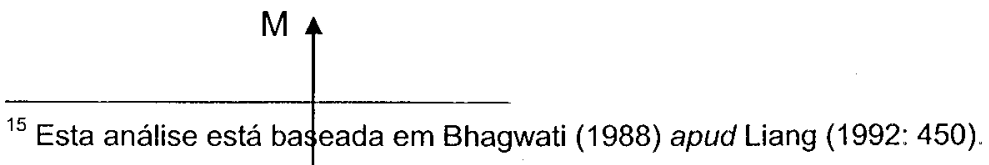




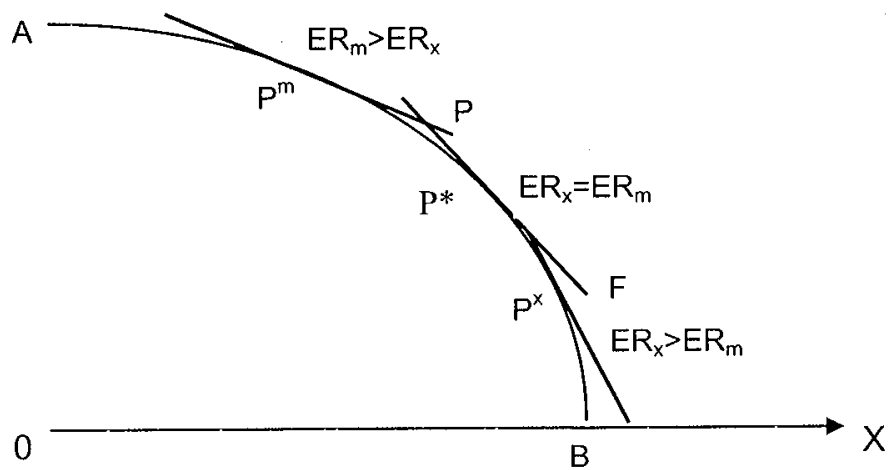

Figura 3.1 - Política comercial no modelo bissetorial

Admitindo que os bens comercializáveis são substitutos entre si na produção, temos:

$$
\frac{\partial X}{\partial \mathrm{P}_{M / H}}<0, \frac{\partial \mathrm{X}}{\partial \mathrm{P}_{X / H}}>0 ; \frac{\partial M}{\partial \mathrm{P}_{M / H}}, \frac{\partial M}{\partial \mathrm{P}_{X / H}}
$$

Na Figura 4.2, a seguir, é ilustrada a relação entre os incentivos comerciais e a produção dos bens comercializáveis no modelo de três setores. Nela, o eixo vertical representa o preço relativo entre os bens exportáveis $\mathrm{e}$ os bens domésticos, indicado por $\mathrm{P}_{\mathrm{X} / \mathrm{H}}$; o eixo horizontal, indicado por $\mathrm{P}_{\mathrm{M} / \mathrm{H}}$, representa a relação entre o preço dos importáveis e dos bens domésticos. Qualquer ponto em um dos 4 quadrantes da figura indica uma determinada combinação dos dois preços relativos. Quaisquer pontos à direita de 1 no eixo do $\mathrm{P}_{\mathrm{MH}}$, decorrentes da interferência da política econômica, indicam um incentivo aos setores competidores com as importações; já os à esquerda de 1 configuram um desincentivo provocado pela política econômica. Passando agora para o eixo vertical $\left(\mathrm{P}_{\mathrm{X} H \mathrm{H}}\right)$, quaisquer pontos acima da unidade (ou seja, nos quadrantes I e II) configuram um incentivo aos setores exportadores; sendo que nos pontos abaixo da unidade indicam um desincentivo aos setores exportadores. Já no ponto $E$ tanto $P_{M / H}$ quanto $P_{X / H}$ são iguais a 1, portanto, configura um ponto de livre comércio, onde são produzidas as quantidades $X_{0}$ e $M_{0}$ dos respectivos bens.

As retas positivamente inclinadas $X X^{\prime}$ e $M M^{\prime}$ indicam os pontos onde são produzidas as quantidades $X_{0}$ e $M_{0}$, respectivamente, dos bens $X$ e $M$. A inclinação positiva de ambas reflete a suposição de que o efeito-preço 
cruzado é negativo ${ }^{16}$. Por exemplo, se $P_{M / H}$ aumenta, $P_{X / H}$ terá que aumentar também para impedir uma diminuição de $X$. Quaisquer pontos acima de $X X$ ' indicam uma produção de $X$ acima de $X_{0}$, a produção de equilíbrio na ausência de qualquer incentivo ou desincentivo ao setor $X$; 0 inverso vale para os pontos abaixo de XX'. A reta $M M^{\prime}$ ' também é positivamente inclinada, só que com uma inclinação maior, decorrente da suposição que o seu efeito-preço é maior que o efeito-preço cruzado. Os pontos à direita de MM' indicam que a produção interna dos bens competidores com as importações é maior que $\mathrm{M}_{0}$; o inverso também vale para os pontos à esquerda de $M M^{\prime}$.

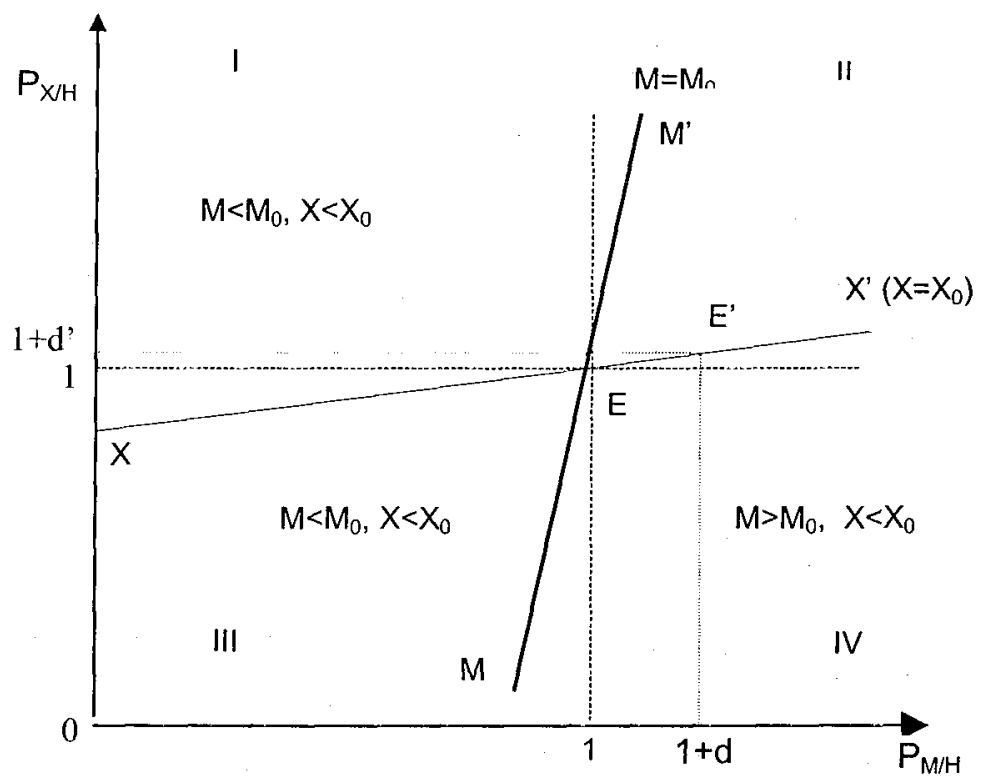

Figura 4.2 - Incentivos comerciais no modelo de três setores

Vê-se, portanto, que os pontos onde $P_{M / H}$ é maior que a unidade representam a presença de incentivos ao setor produtor de bens competidores com importações; ao passo que só nos pontos à direita da reta MM' é que

${ }^{16}$ Liang (1992: 452). 
verificar-se-á aumentos efetivos na produção de $M$. Analogamente, os pontos onde $\mathrm{P}_{\mathrm{X} / \mathrm{H}}$ é maior que 1 verifica-se a presença de incentivos ao setor exportador, e desincentivos nos pontos onde $P_{X / H}$ é menor que a unidade; ao passo que só nos pontos acima de reta $X X^{\prime}$ é que ocorre aumento na produção do bem exportável comparativamente ao seu nível de equilibrio na ausência de qualquer interferência estatal.

A Figura 4.3, a seguir, indica as quatro combinações possíveis de estratégia comercial, onde substituição de importações e promoção às exportações deixam de ser estratégias mutuamente excludentes. No quadrante 1 temos que $P_{X / H}>1$ e $P_{M / H}<1$, significando que existem incentivos ao setor exportador e desincentivos ao setor substituidor de importações; tal estratégia denomina-se de Promoção às Exportações (EP). No quandrante 2 temos $P_{X / H}>1$ e $P_{M / H}>1$, onde são estimulados simultaneamente os setores substituidores de importações e o setor exportador. Tal estratégia (PEP), de proteção contra as importações e de subsídio às exportações, ocorre às expensas do setor produtor de bens não comercializáveis. Segundo Liang (1992: 458), "PEP combines the sectoral orientation of the IS strategy and the market orientation of the EP strategy, seeking to balance the need to optimise the allocation of existing resources and the need to promote desired structural change and develop future strategic resources". As análises empíricas de Liang indicam como exemplo dessa estratégia o caso da Coréia do Sul, freqüentemente citado como exemplo bem-sucedido da estratégia de promoção às exportações.

O quandrante 3 indica uma estrutura de incentivos que não é reconhecida na literatura. Ela representa um viés contra o setor produtor de bens comercializáveis (tanto exportador quanto substituidor de importações), dado que tanto $P_{X / H}$ quanto $P_{M / H}$ são menores que a unidade. Liang denomina tal estratégia de De Facto Import Promotion (DIP), dado que tanto minimiza as exportações quanto maximiza as importações. O termo "de fato" é utilizado para indicar que nem sempre esta situação ocorre por opção dos formuladores da política econômica ${ }^{17}$. Também pode ser visto que uma estratégia de crescimento com endividamento, como tal, não é sustentável no longo prazo, já que trará repercussões no balanço de pagamentos. $O$ quadrante 4 indica uma combinação de preços relativos $\left(P_{X / H}<1\right.$ e $\left.P_{M / H}>1\right)$ que caracterizam uma política de substituição de importações "pura" (IS). No centro do quadro temos o "ponto" $E$, que indica a ausência de interferência governamental nos preços relativos entre os bens comercializáveis e não-comercializáveis, configurando, portanto, uma situação de livre comércio.

${ }^{17}$ Liang (1992: 455). 
Apesar de engenhosa, esta abordagem analítica merece algumas considerações. Em primeiro lugar, a análise procedida baseou-se num modelo de equilibrio parcial, considerando apenas os mercados de bens e serviços. Como é admitido em Liang (1990), foram ignorados os efeitos das estratégias comerciais sobre os mercados de fatores e moeda no longo prazo ${ }^{18}$, além de desconsiderar as implicações sobre bem-estar das políticas comerciais alternativas. Desta forma, as conclusões de sua análise ficam restritas aos mercados de bens e serviços no curto prazo, e assumem ainda - de forma não realística - que os governos são livres para escolher as estratégias comerciais e implementá-las, desconsiderando o impacto dos outros fatores mencionados.

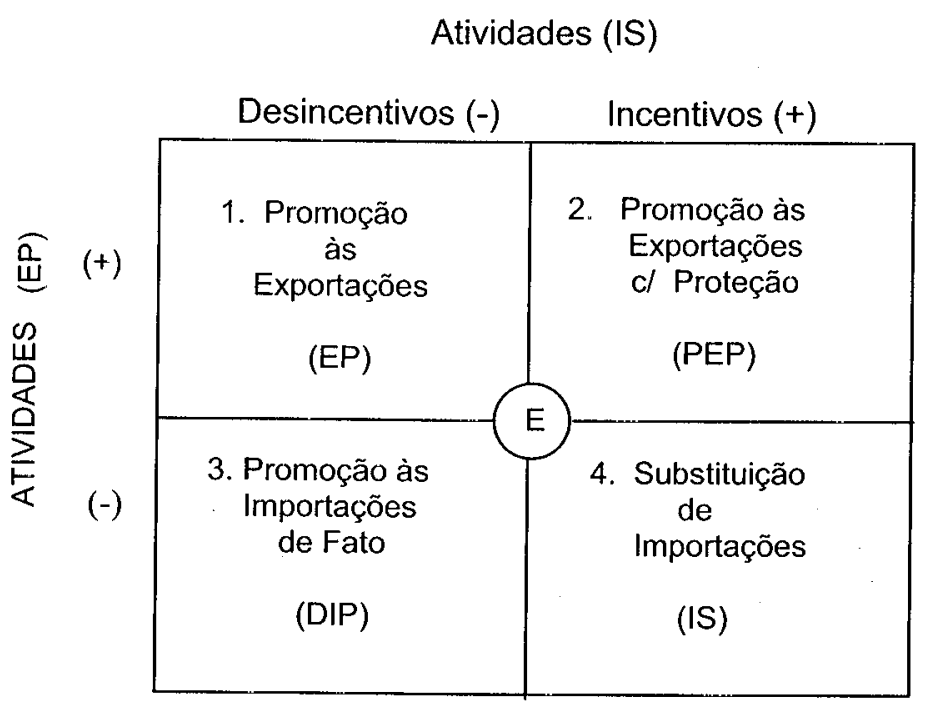

Figura 4.3 - Relação entre incentivos e estratégia comercial

${ }^{18}$ Liang (1990: 195). 
Em segundo lugar, embora seja passivel de mensuração, a estratégia comercial "revelada" de um país - seguindo alguns critérios bemestabelecidos de mensuração da orientação comercial - não são analisados os instrumentos de política necessários para alcançar a estrutura de incentivos desejada ${ }^{19}$. O cuidado na escolha dos instrumentos de política é importante para evitar que uma combinação dos incentivos cruzados anulemse mutuamente, desviando-se dos objetivos pretendidos no início. O gerenciamento dos incentivos deve levar em conta, por exemplo, se as medidas protecionistas de uma estratégia PEP podem ser aquelas típicas de uma estratégia IS.

Este último aspecto revela uma outra limitação da abordagem, principalmente do ponto de vista de política econômica: a nova tipologia de Liang possui natureza descritiva ${ }^{20}$. Desta forma, os resultados que vierem a ser obtidos apresentarão apenas caráter sugestivo de políticas comerciais, devendo o policy maker observar os elementos condicionantes da orientação comercial. Milner (1994) analisa a estrutura de incentivos comerciais requeridas para provocar alterações dos preços relativos - no âmbito de um modelo de equilíbrio geral - e conclui que a classificação ex post da política comercial pode diferir significativamente da estratégia desejada ${ }^{21}$. Para ele, a identificação - ex post - e o planejamento - ex ante - do viés intratradeable não apresenta maiores problemas em nível teórico. Entretanto o viés inter-tradeable/nontradeable é menos suscetivel de controle de política. A razão, segundo ele, decorre da característica endógena do preço dos nontradeables em função das intervenções de política. Milner argumenta que o equilibrio dos preços relativos dependerá da direção e da magnitude relativa dos efeitos-renda e substituição decorrente das políticas comerciais $^{22}$.

A análise de Milner mostra algumas importantes restrições à estrutura analítica de Liang, a qual decorre especialmente do seu caráter de equilíbrio parcial, uma fraqueza reconhecida inclusive por seu autor. Entretanto, esta nova tipologia racionaliza algumas lições extraídas dos países do sudeste asiático no que se refere aos benefícios econômicos do viés pró-tradeable. Neste ponto, Liang rompe com a abordagem tradicional e apresenta uma alternativa ela, abrindo a possibilidade teórica de um mix de política comercial pró-tradeable. As restrições mencionadas por Milner enriquecem a abordagem de Liang ao apresentar seus condicionantes, sem contradizê-la na essência.

\footnotetext{
${ }^{19}$ Liang (1990: 198).

${ }^{20}$ Liang (1990: 198).

${ }^{21}$ Milner (1994), p. 587

22 Ibid., p 590.
} 


\section{5 - CONCLUSÕES}

Na primeira seção deste trabalho apresentamos a defesa estruturalista da substituição de importações industrial como estratégia para superação do subdesenvolvimento. Os argumentos para esta proposição baseavam-se sobretudo na defesa da indústria nascente, a qual necessitaria de incentivos (protecionistas ou não) até ficar apta a concorrer com os produtos das indústrias maduras do exterior.

Na segunda seção apresentamos as críticas à estratégia substitutiva de importações, a qual foi reavaliada posteriormente inclusive pelo portavoz maior do estruturalismo, Raúl Prebisch. Mencionamos que o crescimento por substituição de importações é relativamente fácil na sua primeira fase, em que são substituídas importações (compostas principalmente de bens de consumo) intensivas em fatores produtivos abundantes nos países subdesenvolvidos. Entretanto, como a experiência histórica mostrou, a segunda fase de substituição de importações (bens duráveis, de capital e insumos básicos/intermediários) requer a utilização de fatores de produção escassos nesses países, dificultando a realização desta etapa e produzindo distorções na distribuição de renda. Além disso, a pequena dimensão do mercado implicaria baixo aproveitamento de economias de escala, resultando num nível de renda aquém da sua potencialidade.

A dicotomia entre estratégias de substituição de importações versus promoção às exportações é totalmente válida num modelo bissetorial, em que são produzidos um bem competidor com as importações e outro exportável. Entretanto, conforme Liang (1992), a introdução de um terceiro setor - nontradeable - abre a possibilidade teórica para uma política comercial que incentive a ambos os setores tradeables, ou mesmo nenhum. Este arcabouço analítico permite a identificação de cinco estratégias de "incentivos" comerciais, as quais foram analisadas na terceira seção deste trabaIho. Entretanto, conforme Milner (1994), a internalização pelos agentes destas políticas de incentivos irá depender dos seus efeitos substituição, complementaridade e/ou renda sobre os preços relativos de equilíbrio.

Em resumo, vimos que a abordagem estruturalista sobre a substituição de importações carece de alguns reparos, especialmente no tocante à eficiência econômica das alocações de recursos. Entretanto, ao contrário do que estabelece a teoria sobre política comercial tradicional, Liang monta um arcabouço analítico indicando a possibilidade de uma combinação de estratégias. Esta estratégia "equilibrada" teria a propriedade de minimizar as distorções introduzidas pela politica de substituição de importações; por outro lado, recupera a proposição clássica da estratégia estruturalista que é a de mudança no padrão de vantagens comparativas. Esta recente contri. buição sugere uma reflexão mais sofisticada sobre estratégias alternativas 
de desenvolvimento, enriquecendo o debate sobre a importância da política comercial.

\section{BIBLIOGRAFIA}

ABREU, M. P. (org.) A ordem do progresso - cem anos de política econômica republicana 1889-1989. Rio de Janeiro: Campus, 1992.

BHAGWATI, J. N. Export-promoting trade strategy: issues and evidence. The World Bank Research Observer, 3(1), jan. 1988.

CHENERY, H. B. Patterns of industrial growth. The American Economic Review, 50(4), p. 624-654, sept. 1960.

CASTELO BRANCO, F. P. de. Importaçöes de bens de capital e substituição de importações: algumas considerações sobre o problema recente no Brasil. Dissertação (mestrado). Departamento de Economia/Universidade de Brasilia. Brasilia, 1976.

DESAI, Padma. Alternative measure of import substitution. Oxford Economic Papers, 21(3), p. 312-324, nov. 1969.

FRITSCH, W. e FRANCO, G. H. B. Politica industrial, competitividade e industrialização: aspectos da experiência brasileira recente. Planejamento e Politicas Públicas, n. 3, p. 75-99, jun. 1990

LIANG. Beyond import substitution and export promotion: a new tipology of trade strategies with empirical verification and policy analysis Dissertation (PhD). Indiana University, 1990.

Beyond import substitution and export promotion: a new tipology of trade strategies. The Journal of Development Studies, 28(3), p. 447-472, april 1992.

MILNER, $C$. Trade strategy and revealed trade bias: an evaluation for a small industrializing economy. World Development, 22(4), p. 587-599, 1994

Relative incentives and trade strategies: typologies and possibilities Economic Record, 71(214), p. 230-239, sept. 1995.

MITRA, P. K. Import substitution and export promotion as means to industrialization. Economia Internazionale, v. XXVII, n. 3-4, p. 524-537, ago-nov. 1974.

MORLEY, S. A. e SMITH, G. W. On the measurement of import substitution. American Economic Review, 60(4), p. 728-735, sept. 1970.

ORENSTEIN, L. e SOCHACZEWSKI, A. C. Democracia com desenvolvimento: 1956-1961. In: ABREU, M. P. (org.). A ordem do progresso - cem anos de política econômica republicana 1889-1989. Rio de Janeiro: Campus, 1992.

PAULA PINTO, M. B.; MAIA, M. M.; BERES, N.; MALHEIROS, P. C. F.; SOUZA, A. $\mathrm{L}$. S. O custo dos recursos domésticos e a competividade da agricultura brasileira. v. 1, Brasilia, 1994.

PREBISCH, R. El desarrollo económico de América Latina y algunos de sus principales problemas. Boletin Económico de América Latina, VIII, 1949.

Towards a dynamic development policy for Latin America. New York: United Nations, 1963.

SÖDERSTEN, B. e REED, G. International economics. Macmillan Press Ltd, 1994.

SOUZA, N. de J. Desenvolvimento econômico. São Paulo: Atlas, 1993 
WILLIAMSON, J. A economia aberta e a economia mundial - um texto de economia internacional. Rio de Janeiro: Campus, 1989. 